\title{
PENGARUH PERBEDAAN PROPORSI PENAMBAHAN KONJAK TERHADAP SIFAT FISIK, KIMIA DAN ORGANOLEPTIK JELI SARI BUAH ANGGUR HITAM (Vitis vinifera L.var Alphonso Lavalle) \\ The Effect of Differences in the Proportion of Adding Konjac on Physical, Chemical and Organoleptic of Black Grape (Vitis vinifera L.var Alphonso Lavalle) Jelly. \\ Rena Anggreana ${ }^{1}$, Ika Fitriana ${ }^{2}$, Dewi Larasati ${ }^{3}$ \\ ${ }^{1}$ Mahasiswa Teknologi Hasil Pertanian Universitas Semarang \\ ${ }^{2,3}$ Staff Pengajar Teknologi Hasil Pertanian Universitas Semarang Jl. Soekarno-Hatta Tlogosari Semarang-50196
}

ABSTRAK

Pengaruh Perbedaan Proporsi Penambahan Konjak Terhadap Sifat Fisik, kimia Dan Organoleptik Jeli Sari Buah Anggur Hitam, Rena Anggreana, Fakultas Teknologi Pertanian, Universitas Semarang. Jeli adalah produk yang terbuat dari Sari buah dan dimasak dengan gula, yang berwarna jernih, transparan dan cukup kukuh mempertahankan bentuknya apabila dikeluarkan dari wadah. Jeli adalah bentuk makanan semi padat yang penampakan lebih jernih, kenyal, serta transparan. Salah satu hal penting dalam pembuatan jeli adalah bahan pengental. Di industri pangan, konjak digunakan sebagai pembentuk gel, pengental, pemantap, emulsifier, dan pembentuk film. Pada pembuatan jeli menggunakan anggur hitam yang mempunyai nilai gizi baik seperti vitamin, mineral, karbohidrat, dan senyawa fitokimia. Anggur hitam terkenal kaya akan antioksidan, di dalamnya mengandung vitamin $\mathrm{C}$, provitamin $\mathrm{A}$, vitamin B1, B2, mineral, besi, fosfor, kalsium, kalium, serat, kadar air dan asam sitrat yang tinggi.

Penelitian ini bertujuan untuk mengetahui pengaruh perbedaan proporsi penambahan konjak pada pembuatan jeli terhadap sifat fisik, kimia, dan organoleptik. Penelitian dilakukan di Laboratorium Rekayasa Pangan dan di Laboratorium Kimia Pangan, Fakultas Teknologi Pertanian, Universitas Semarang, pada bulan Januari 2018. Penelitian menggunakan metode RAK (Rancangan Acak Kelompok) satu faktor yaitu pengaruh perbedaan proporsi penambahan konjak pada jeli perlakuan $1(1 \%), 2$ $(2 \%), 3(3 \%), 4(4 \%), 5(5 \%), 6(6 \%)$.

Berdasarkan hasil penelitian menunjukkan bahwa perbedaan proporsi penambahan konjak pada pembuatan jeli berpengaruh nyata terhadap antioksidan, vitamin $\mathrm{C}$, kadar air, tekstur, sineresis, dan organoleptik (rasa, tekstur, dan warna). Hasil perlakuan terbaik adalah perlakuan ke 3 dengan kandungan aktivitas antioksidan 25,80\%, vitamin C 1,75 mg/g, kadar air 19,24\%, kekerasan 428,27 gf, elastisitas 9,26 N/m2, kekenyalan 118,49 gf, sineresis 2,91\%, skor rasa 3,55, skor tekstur 3,75, skor warna 3,70.

Kata kunci : Jeli, Anggur hitam, Konjak

\section{ABSTRACT}

The Effect of Differences in the Proportion of Adding Konjac on Physical, Chemical and Organoleptic of Black Grape (Vitis vinifera L.var Alphonso Lavalle) Jelly, Rena Anggreana, Faculty of Agricultural Technology, Semarang University. Jelly is a product made from fruit juice and cooked with sugar, clear color, transparent and strong enough to maintain its shape when removed from the container. Jelly is a form of semi-solid food that looks clearer, chewy, and transparent. One of the important things in making jelly is thickening material. In the food industry, konjac is used as a gelling, thickener, feeder, emulsifier, and film former. In making jelly using black grape that has good nutritional value such as vitamins, minerals, carbohydrates, and phytochemical compounds. The famous black grape is rich in antioxidants, 
containing vitamin $C$, provitamin A, vitamin B1, B2, minerals, iron, phosphorus, calcium, potassium, fiber, water content and high citric acid.

This research has purpose to know the effect of differences in the proportion of adding konjac on the manufacture of jelly to the physical, chemical, and organoleptic. The research was conducted at Food Engineering Laboratory and in Food Chemistry Laboratory, Faculty of Agricultural Technology, Semarang University, in January 2018. The research used RAK (Group Random Design) one factor that is difference of proportion of konjac addition on 1 (1\%), $2(2 \%), 3(3 \%), 4(4 \%), 5(5 \%), 6(6 \%)$.

Based on the result of the research shows that the difference of proportion of konjac addition to jelly making has significant effect on antioxidant, vitamin $C$, water content, texture, sineresis, and organoleptic (taste, texture, and color). The best treatment result is 3rd treatment with antioxidant activity $25,80 \%$, vitamin $C 1,75 \mathrm{mg} / \mathrm{g}$, water content $19,24 \%$, hardness 428,27 gf, elasticity 9,26 N/m2, elasticity 118,49 gf, sineresis 2,91\%, taste score 3,55, texture score 3,75, color score 3,70.

Keywords: Jelly, Black grape, Konjac

\section{PENDAHULUAN}

Anggur hitam dengan nama ilmiah Vitis vinfera L. var. Alphonso Lavallee merupakan salah satu buah unggulan di Bali. Jenis anggur ini memiliki warna khas yaitu hitam keunguan. Anggur hitam berbentuk bulat, kulit buahnya tipis, dagingnya seperti bulir yang mengandung banyak air. Anggur hitam memiliki kandungan antioksidan yang sangat tinggi baik untuk menangkal radikal bebas dalam tubuh. Daya jual anggur hitam cenderung lebih rendah dibanding anggur lainnya, hal ini disebabkan karena rasanya yang lebih masam dan ukurannya kecil, untuk itu perlu adanya inovasi untuk meningkatkan nilai gunanya.

Jeli adalah makanan setengah padat yang terbuat dari sari buah-buahan dan gula. Syarat jeli yang baik ialah transparan, mudah dioleskan dan mempunyai aroma dan rasa buah asli (Koswara, 2011).

Salah satu hal penting dalam pembuatan jeli adalah bahan pengental. Konjak adalah serat pangan larut air yang berasal dari umbi konjak (Amorphophallus konjac). Umbi konjak segar rata-rata mengandung bahan kering sebesar 13\% dimana 64\% dari bahan kering tersebut adalah glukomannan dan 30\% dari bahan kering adalah pati (Thomson, 1997). Menurut Deptan (2010), senyawa konjak mempunyai sifat-sifat khas yaitu larut dalam air, membentuk gel, merekat, mengembang, transparan, mencair, mengendap. Konjak dapat larut dalam air dingin dan membentuk larutan yang sangat kental. 


\section{METODE PENELITIAN}

\section{Tempat dan Waktu Penelitian}

Penelitian ini dilaksanakan pada bulan Januari 2018 sampai selesai di Laboratorium Kimia dan Biokimia, Laboratorium Rekayasa Pangan dan Laboratorium Uji Indrawi Unversitas Semarang.

\section{Alat dan Bahan Penelitian}

Alat yang digunakan dalam penelitian adalah timbangan digital, beker gelas, pengaduk, panci, spatula, nampan, baskom, cetakan agar - agar, sendok, lemari pendingin, cawan porselen, desikator, oven, tang kurs, Tekstur Analizer, blender, kertas saring, mortar, stamper, pipet volume 5, 10 dan $25 \mathrm{ml}$, labu takar 100 dan $250 \mathrm{ml}$, gelas ukur 50 dan $100 \mathrm{ml}$, erlenmeyer $250 \mathrm{ml}$, statif, buret $25 \mathrm{ml}$, gelas beker 100, $250 \mathrm{ml}$, spektrofotometer, dan alat- alat gelas lain.

Bahan baku yang digunakan anggur hitam, konjak (nutrijel plain), air, gula pasir.

\section{PROSEDUR PENELITIAN}

Penelitian yang dilakukan merupakan penelitian eksperimental. Perlakuan yang ditetapkan dalam penelitian ini ditetapkan secara trial and error melalui penelitian pendahuluan (pra penelitian).

\section{RANCANGAN PERCOBAAN}

Rancangan percobaan yang digunakan dalam penelitian adalah Rancangan Acak Kelompok (RAK) satu faktor yaitu perbedaan proporsi penambahan konjak yang terdiri dari 6 perlakuan 3 kali ulangan. Adapun proporsi konjak antar perlakuan sebagai berikut : P1 (1\%), P2 (2\%), P3 (3\%), P4 (4\%), P5 (5\%), P6 (6\%). Sedangkan variabel pengamatan yaitu: sifat kimia (kadar air, vitamin C, aktivitas antioksidan), sifat fisik (kekerasan, kekenyalan, elastisitas, sineresis), dan sifat organoleptik (rasa, warna, tekstur) jeli sari buah anggur hitam.

\section{Tabel. 1. Rasio konjak dan sari buah anggur hitam}

\begin{tabular}{|llll|}
\hline Perlakuan & \multicolumn{2}{l|}{ Konjak } & Sari Buah \\
\hline P1 & $1 \%$ & $5 \mathrm{gr}$ & $500 \mathrm{ml}$ \\
\hline P2 & $2 \%$ & $10 \mathrm{gr}$ & $500 \mathrm{ml}$ \\
\hline P3 & $3 \%$ & $15 \mathrm{gr}$ & $500 \mathrm{ml}$ \\
\hline P4 & $4 \%$ & $20 \mathrm{gr}$ & $500 \mathrm{ml}$ \\
\hline P5 & $5 \%$ & $25 \mathrm{gr}$ & $500 \mathrm{ml}$ \\
\hline P6 & $6 \%$ & $30 \mathrm{gr}$ & $500 \mathrm{ml}$ \\
\hline
\end{tabular}

\section{TAHAPAN PENELITIAN}

Siapkan bahan yang digunakan. Buah anggur hitam di blansing dengan suhu $70^{\circ} \mathrm{C}$ selama 2 menit. Haluskan buah anggur hitam 500 gr menggunakan blender dengan penambahan air (1:1), lalu disaring untuk memisahkan ampas dan sari buah. Sari buah anggur hitam kemudian diambil $500 \mathrm{ml}$. Timbang jeli konjak sesuai variasi perlakuan yang telah ditentukan $(1 \%, 2 \%, 3 \%, 4 \%$, $5 \%, 6 \%)$. Tambahkan $10 \%$ gula, aduk hingga larut.. Masak campuran tersebut diatas kompor sampai suhu $90^{\circ} \mathrm{C}$ selama 2 menit sambil diaduk. Matikan api kompor, tuangkan larutan jeli kedalam cetakan. Simpan dalam lemari pendingin suhu $10^{\circ} \mathrm{C}$. Jika sudah mengeras, keluarkan jeli dari cetakan 


\section{HASIL DAN PEMBAHASAN}

\section{Sineresis}

Sineresis adalah peristiwa keluarnya atau merembesnya cairan dari suatu gel (Winarno,1992). Semakin tinggi nilai sineresisnya, maka semakin rendah mutu dari produk jeli tersebut. Berdasarkan analisa sidik ragam menunjukkan bahwa perbedaan proporsi penambahan konjak berpengaruh nyata $(\mathrm{p}<0,05)$ terhadap nilai sineresis pada jeli. Rerata hasil uji sineresis dengan perlakuan perbedaan proporsi penambahan konjak berkisar antara 2,52\% sampai 3,50\%. Nilai rerata tingkat sineresis ditunjukan pada Tabel 2.

\section{Tabel.2. Hasil Uji Kadar Sineresis (\%)}

\begin{tabular}{|ll|}
\hline Kode Perlakuan & Konjak \\
\hline P1 & $3,50^{ \pm} 0,04^{\mathrm{f}}$ \\
\hline P2 & $3,23^{ \pm} 0,06^{\mathrm{e}}$ \\
\hline P3 & $2,91^{ \pm} 0,07^{\mathrm{d}}$ \\
\hline P4 & $2,78^{ \pm} 0,02^{\mathrm{c}}$ \\
\hline P5 & $2,66^{ \pm} 0,03^{\mathrm{b}}$ \\
\hline P6 & $2,52^{ \pm} 0,03^{\text {a }}$ \\
\hline
\end{tabular}

Keterangan: Superskrip dengan huruf yang berbeda pada kolom yang sama menunjukkan beda nyata $(\mathrm{p}<0,05)$

Pada Tabel.2. menunjukkan bahwa setelah diuji lanjut dengan BNJ 5\%, terdapat perbedaan nyata antar masing - masing perlakuan. Pada perlakuan pertama dengan konsentrasi konjak $1 \%(3,50 \%)$ memiliki tingkat sineresis paling tinggi kemudian mengalami penurunan. Perlakuan ke 6 dengan konsentrasi konjak paling tinggi memiliki nilai sineresis paling rendah. Perbedaan penambahan proporsi bahan pembentuk gel pada jeli berpengaruh pada tingkat sineresisnya. Hal ini sesuai dengan pendapat Agustin, dkk (2014) pada penelitian pembuatan jelly drink belimbing wuluh, semakin tinggi konsentrasi pembentuk gel yang ditambahkan maka nilai sineresis jelly drink belimbing wuluh semakin turun. Hal ini diduga semakin besarnya penggunaan konsentrasi gelling agent, maka akan terbentuk struktur double helix yang kuat sehingga dapat menangkap air sekaligus mengikatnya sehingga molekul air dalam gel tidak mudah lepas, hal ini akan mengurangi terjadinya sineresis.

Menurut hasil penelitian Azizah (2012), menunjukkan bahwa peningkatan jumlah konjak ternyata dapat mengurangi sineresis pada permen jeli. Penambahan konjak glukomanan dalam gel agar maupun kappa karagenan dapat meningkatkan kekuatan dan elastisitas gel, serta menurunkan tingkat sineresisnya (Tako dan Nakamura, 1988; Goycoolea et al, 1995).

\section{Nilai Kekerasan (Hardness)}

Menurut Rosental (1999), kekerasan didefinisikan sebagai gaya yang diberikan hingga terjadi perubahan bentuk (deformasi) pada objek. Kekerasan merupakan salah satu kriteria penting pada jeli. Berdasarkan analisa sidik ragam menunjukkan bahwa perbedaan proporsi penambahan konjak berpengaruh nyata $(\mathrm{p}<0,05)$ terhadap nilai kekerasan pada jeli. Nilai rerata kekerasan ditunjukan pada Tabel 3. 
Tabel. 3. Hasil Uji Kekerasan

\begin{tabular}{|ll|}
\hline Kode Perlakuan & Nilai \\
\hline P1 & $200,86^{ \pm} 4,09^{\mathrm{a}}$ \\
\hline P2 & $316,43^{ \pm} 2,82^{\mathrm{b}}$ \\
\hline P3 & $428,27^{ \pm} 2,03^{\mathrm{c}}$ \\
\hline P4 & $474,60^{ \pm} 1,15^{\mathrm{d}}$ \\
\hline P5 & $514,10^{ \pm} 3,90^{\mathrm{e}}$ \\
\hline P6 & $561,01^{ \pm} 1,63^{\mathrm{f}}$ \\
\hline
\end{tabular}

Keterangan : Superskrip dengan huruf yang berbeda pada kolom yang sama menunjukkan beda nyata $(\mathrm{p}<0,05)$.

Tabel 3. menunjukkan bahwa setelah diuji lanjut dengan BNJ 5\%, terdapat perbedaan nyata antar masing - masing perlakuan. Pada perlakuan pertama dengan konsentrasi konjak $1 \%$ (200,86 gf) memiliki nilai hardness paling rendah kemudian mengalami peningkatan di setiap penambahan konsentrasi konjak. Perlakuan ke 1 dengan konsentrasi konjak paling rendah memiliki nilai hardness paling rendah. Perlakuan ke 6 dengan konsentrasi konjak paling tinggi memiliki nilai hardness paling tinggi. Perbedaan penambahan proporsi bahan pembentuk gel pada jeli berpengaruh pada tingkat hardness. Semakin sedikit konjak yang ditambahkan maka gel yang dibentuk akan bersifat berair atau lunak, sebaliknya semakin banyak konjak yang ditambahkan tentunya gel yang dihasilkan akan semakin padat dan kaku.

Hal ini sesuai dengan pendapat Azizah (2012), nilai hardness yang semakin tinggi menujukkan semakin keras permen jeli dan sebaliknya nilai hardness semakin rendah menujukkan semakin lunak permen jeli. Peningkatan konsentrasi konjak dalam campuran menyebabkan kekerasan jeli semakin meningkat. Hal ini diduga kerena konjak bersifat membentuk gel. Gel yang dihasilkan oleh konjak dapat bersifat reversible atau thermoirreversible (Thomson, 1997). Menurut Deptan (2010), konjak dapat membentuk larutan yang sangat kental di dalam air.

\section{Nilai Kekenyalan (Gumminess)}

Menurut Rosental (1999), kekenyalan (gumminess/stickiness) didefinisikan sebagai tenaga yang dibutuhkan untuk menghancurkan (memecah) pangan semi padat menjadi bentuk yang siap untuk ditelan. Kekenyalan merupakan salah satu karakteristik penting pada permen termasuk jeli. Berdasarkan analisa sidik ragam menunjukkan bahwa perbedaan proporsi penambahan konjak berpengaruh nyata $(\mathrm{p}<0,05)$ terhadap nilai kekenyalan pada jeli. Nilai rerata kekenyalan ditunjukan pada Tabel 4.

Tabel. 4. Hasil Uji Kekenyalan (gf)

\begin{tabular}{|ll|}
\hline Kode Perlakuan & Nilai \\
\hline P1 & $28,32^{ \pm} 0,47^{\mathrm{a}}$ \\
\hline P2 & $71,35^{ \pm} 3,11^{\mathrm{b}}$ \\
\hline P3 & $118,49^{ \pm} 1,69^{\mathrm{c}}$ \\
\hline P4 & $164,53^{ \pm} 3,32^{\mathrm{d}}$ \\
\hline P5 & $214,19^{ \pm} 0,91^{\mathrm{e}}$ \\
\hline P6 & $271,77^{ \pm} 7,24^{\mathrm{f}}$ \\
\hline
\end{tabular}


Keterangan: Superskrip dengan huruf yang berbeda pada kolom yang sama menunjukkan beda nyata $(\mathrm{p}<0,05)$.

Pada perlakuan pertama dengan konsentrasi konjak $1 \%(28,32$ gf) memiliki nilai gumminess paling rendah kemudian mengalami peningkatan pada konsentrasi konjak $2 \%(71,35$ gf), 3\% (118,49 gf), 4\% (164,53 gf), 5\% (214,19 gf), 6\% (271,77 gf). Perlakuan ke 1 dengan konsentrasi konjak paling rendah memiliki nilai gumminess paling rendah. Perlakuan ke 6 dengan konsentrasi konjak paling tinggi memiliki nilai gumminess paling tinggi. Nilai kekenyalan dipengaruhi oleh nilai kekerasan yang ditunjukkan dengan penentuan nilai kekenyalan dengan mengalikan nilai kekerasan dengan luasan di bawah kurva penekanan kedua dibagi dengan luasan di bawah kurva pada penekanan pertama. Penambahan konjak yang semakin banyak menyebabkan cairan yang dihasilkan semakin kental, sehingga jeli yang dihasilkan semakin kenyal tidak berair.

Semakin tinggi konsentrasi konjak yang ditambahkan maka nilai hardness semakin naik, semakin tinggi nilai hardness pada jeli maka akan semakin tinggi nilai gumminessnya. Gel konjak membentuk gel yang kuat, elastis, tahan leleh ketika dilakukan pemanasan (Azizah, 2012). Peningkatan konsentrasi konjak dalam campuran menyebabkan kekenyalan jeli semakin meningkat. Hal ini sesuai dengan pendapat Malik (2010), semakin banyak penambahan bahan pembentuk gel akan mengakibatkan jeli menjadi keras tidak lembek.

\section{Nilai Elastisitas (Springiness)}

Menurut Rosental (1999), elastisitas didefinisikan sebagai laju suatu objek untuk kembali kebentuk semula setelah terjadi perubahan bentuk (deformasi). Berdasarkan analisa sidik ragam menunjukkan bahwa perbedaan proporsi penambahan konjak berpengaruh nyata $(\mathrm{p}<0,05)$ terhadap nilai elastisitas pada jeli. Nilai rerata elastisitas ditunjukan pada Tabel 5.

Tabel 5. Hasil Uji Elastisitas (N/m²)

\begin{tabular}{|ll|}
\hline Kode Perlakuan & Nilai \\
\hline P1 & $28,32^{ \pm} 0,47^{\text {a }}$ \\
\hline P2 & $71,35^{ \pm} 3,11^{\mathrm{b}}$ \\
\hline P3 & $118,49^{ \pm} 1,69^{\mathrm{c}}$ \\
\hline P4 & $164,53^{ \pm} 3,32^{\mathrm{d}}$ \\
\hline P5 & $214,19^{ \pm} 0,91^{\mathrm{e}}$ \\
\hline P6 & $271,77^{ \pm} 7,24^{\mathrm{f}}$ \\
\hline
\end{tabular}

Keterangan: Superskrip dengan huruf yang berbeda pada kolom yang sama menunjukkan beda nyata $(\mathrm{p}<0,05)$.

Tabel 5. menunjukkan bahwa setelah diuji lanjut dengan BNJ 5\%, terdapat perbedaan nyata antar masing - masing perlakuan. Pada perlakuan pertama dengan konsentrasi konjak $1 \%$ $\left(10,11 \mathrm{~N} / \mathrm{m}^{2}\right)$ memiliki nilai springiness paling tinggi kemudian mengalami penurunan pada konsentrasi konjak $2 \%\left(9,68 \mathrm{~N} / \mathrm{m}^{2}\right), 3 \%\left(9,26 \mathrm{~N} / \mathrm{m}^{2}\right), 4 \%\left(8,79 \mathrm{~N} / \mathrm{m}^{2}\right), 5 \%\left(8,41 \mathrm{~N} / \mathrm{m}^{2}\right), 6 \%$ $\left(7,44 \mathrm{~N} / \mathrm{m}^{2}\right)$. Perlakuan ke 1 dengan konsentrasi konjak paling rendah memiliki nilai paling tinggi berarti tingkat elastisitas paling rendah. Perlakuan ke 6 dengan konsentrasi konjak paling tinggi memiliki nilai paling rendah berarti tingkat elastisitas paling tinggi. Semakin sedikit konjak yang ditambahkan, tentunya tekstur jeli yang dihasilkan akan semakin lunak dan berair, hal ini akan menurunkan tingkat elastisitas dari jeli. Jeli yang lunak bila ditekan teksturnya akan mudah rusak karena banyaknya air yang terkandung di dalamnya. Semakin tinggi konsentrasi konjak 
yang ditambahkan maka daya elastisitas jeli semakin naik. Gel konjak membentuk gel yang kuat, tahan leleh ketika dilakukan pemanasan (Azizah, 2012). Penggunaan konjak dalam pembuatan jeli sangat membantu untuk menghasilkan jeli dengan tekstur yang lebih elastis dibandingkan menggunakan karagenan. Semakin banyak konjak yang ditambahkan maka jeli akan semakin elastis tidak berair (Imeson, 2000).

Semakin tinggi konsentrasi konjak yang ditambahkan maka daya elastisitas jeli semakin naik. Gel konjak membentuk gel yang kuat, tahan leleh ketika dilakukan pemanasan (Azizah, 2012). Penggunaan konjak dalam pembuatan jeli sangat membantu untuk menghasilkan jeli dengan tekstur yang lebih elastis dibandingkan menggunakan karagenan. Semakin banyak konjak yang ditambahkan maka jeli akan semakin elastis tidak berair (Imeson, 2000).

\section{Kadar Air}

Kandungan air dalam bahan makanan ikut menentukan daya terima, kesegaran dan daya tahan bahan makanan (Winarno, 1992). Kadar air pada jeli seharusnya tidak lebih dari $20 \%$ fraksi massa (SNI.3547-2-2008).

Berdasarkan analisa sidik ragam menunjukkan bahwa perbedaan proporsi penambahan konjak berpengaruh nyata $(\mathrm{p}<0,05)$ terhadap kadar air pada jeli. Nilai rerata kadar air ditunjukan pada Tabel 6.

\section{Tabel 6. Hasil Uji Kadar Air (\%)}

\begin{tabular}{|ll|}
\hline Kode Perlakuan & Nilai \\
\hline P1 & $17,28^{ \pm} 0,00^{\text {a }}$ \\
\hline P2 & $8,35^{ \pm} 0,06^{\mathrm{b}}$ \\
\hline P3 & $19,24^{ \pm} 0,02^{\mathrm{c}}$ \\
\hline P4 & $20,19^{ \pm} 0,01^{\mathrm{d}}$ \\
\hline P5 & $21,06^{ \pm} 0,09^{\mathrm{e}}$ \\
\hline P6 & $22,60^{ \pm} 0,02^{\mathrm{f}}$ \\
\hline
\end{tabular}

Keterangan: Superskrip dengan huruf yang berbeda pada kolom yang sama menunjukkan beda nyata $(\mathrm{p}<0,05)$.

Tabel 6. menunjukkan bahwa setelah diuji lanjut dengan BNJ 5\%, terdapat perbedaan nyata antar masing - masing perlakuan. Pada perlakuan pertama dengan konsentrasi konjak $1 \%$ $(17,28 \%)$ memiliki nilai kadar air paling rendah kemudian mengalami peningkatan pada konsentrasi konjak $2 \%$ (18,35\%), 3\% (19,24\%), 4\% (20,19\%), 5\% (21,06\%), 6\% (22,60\%). Perlakuan ke 1 dengan konsentrasi konjak paling rendah memiliki nilai kadar air paling rendah. Perlakuan ke 6 dengan konsentrasi konjak paling tinggi memiliki nilai kadar air paling tinggi. Bila melihat nilai rerata hasil kadar air dan dibandingkan dengan acuan pada SNI.35472-2008, kadar air jeli dengan konsentrasi 5\% dan 6\% melebihi standar yang ditentukan, hal ini diduga berkaitan dengan konsentrasi konjak yang ditambahkan. Peningkatan konsentrasi konjak dalam campuran menyebabkan kekerasan dan viskositas jeli semakin meningkat dan air yang terikat semakin banyak.

Menurut Agustin, dkk (2014), semakin tinggi konsentrasi gelling agent yang ditambahkan maka nilai viskositas jeli drink belimbing wuluh semakin naik. Hal ini diduga konjak akan mengikat air dalam jumlah besar yang menyebabkan ruang antar partikel menjadi lebih sempit sehingga semakin banyak air yang terikat dan terperangkap menjadikan larutan bersifat keras. Hal ini sesuai dengan pernyataan Widyaningtyas dan Susanto (2014) bahwa perbedaan kadar air dikarenakan penambahan hidrokoloid yang dapat meningkatkan kadar air. Semakin 
tinggi konsentrasi hidrokoloid maka air yang terikat dalam jaringan hidrokoloid lebih banyak. Air yang terukur sebagai kadar air adalah air bebas dan air teradsorbsi dimana air teradsorbsi ini merupakan air yang terikat dalam jaringan hidrokoloid (Putri, dkk., 2013).

\section{Kadar Vitamin C}

Vitamin $\mathrm{C}$ merupakan golongan vitamin larut air. Vitamin ini merupakan vitamin yang mudah rusak. Vitamin $\mathrm{C}$ mudah teroksidasi dan proses tersebut dipercepat oleh panas, sinar, alkali, enzim, oksidator serta oleh katalis tembaga dan besi (Winarno, 1997). Berdasarkan analisa sidik ragam menunjukkan bahwa perbedaan proporsi penambahan konjak berpengaruh nyata $(\mathrm{p}<0,05)$ terhadap kadar vitamin $\mathrm{C}$ pada jeli. Nilai rerata kadar vitamin $\mathrm{C}$ ditunjukan pada Tabel 7.

\section{Tabel 7. Hasil Uji Vitamin C (mg/g)}

\begin{tabular}{|ll|}
\hline Kode Perlakuan & Nilai \\
\hline P1 & $1,47^{ \pm} 0,03^{\mathrm{a}}$ \\
\hline P2 & $1,67^{ \pm} 0,02^{\mathrm{b}}$ \\
\hline P3 & $1,75^{ \pm} 0,01^{\mathrm{c}}$ \\
\hline P4 & $1,91^{ \pm} 0,02^{\mathrm{d}}$ \\
\hline P5 & $2,16^{ \pm} 0,01^{\mathrm{e}}$ \\
\hline P6 & $2,19^{ \pm} 0,02^{\mathrm{e}}$ \\
\hline
\end{tabular}

Keterangan: Superskrip dengan huruf yang berbeda pada kolom yang sama menunjukkan beda nyata $(\mathrm{p}<0,05)$.

Hasil uji lanjut dengan BNJ 5\% menunjukkan bahwa setiap perlakuan memiliki perbedaan yang nyata kecuali perlakuan $5(2,16 \mathrm{mg} / \mathrm{g})$ dan $6(2,19 \mathrm{mg} / \mathrm{g})$ yang tidak berbeda nyata di antara keduanya. Bila dilihat dari rerata hasil uji kadar vitamin $\mathrm{C}$, ditemukan adanya penurunan kandungan vitamin $\mathrm{C}$ pada anggur hitam. Vitamin $\mathrm{C}$ yang terkandung dalam anggur hitam yaitu 10,8 mg (Anonim, 2018) kemudian mengalami penurunan setelah dilakukan proses pembuatan jeli. Vitamin $\mathrm{C}$ merupakan vitamin yang paling mudah rusak. Disamping sangat larut dalam air, vitamin $\mathrm{C}$ mudah teroksidasi dan proses tersebut dipercepat oleh panas, sinar, alkali oksidator serta katalis tembaga dan besi (Muchtadi, 1992).

Vitamin $\mathrm{C}$ yang tersisa di jeli cenderung rendah dengan tingginya kadar air pada jeli. Vit $\mathrm{C}$ merupakan salah satu vitamin yang sangat mudah larut dalam air. Semakin tinggi konsentrasi konjak yang ditambahkan maka kadar air jeli semakin tinggi berarti vitamin $\mathrm{C}$ yang terkandung tidak akan banyak yang terlarut. Hal ini disebabkan karena konsentrasi gelling agent yang tinggi mampu membentuk disperse koloid (struktur double helix) lebih banyak dan kuat sehingga akan menghambat oksidasi vitamin $\mathrm{C}$ dan akan lebih dapat mempertahankan vitamin $\mathrm{C}$. Dengan struktur double helix yang tinggi maka lebih kuat melindungi vitamin $\mathrm{C}$ dengan matriksnya yang kuat. Semakin keras gel yang dibentuk maka oksigen atau kofaktor-kofaktor yang dapat mempercepat oksidasi vitamin C dapat dihambat (Agustin,dkk , 2014). Peningkatan konsentrasi pembentuk gel akan meningkatkan tekstur (kekerasan jeli), total asam, tingkat kesukaan, meningkatkan kestabilan vitamin C, dan menurunkan kesukaan warna (Anonimª, 2010). 


\section{Aktivitas Antioksidan}

Anggur dipakai sebagai terapi kesehatan karena mangandung magnesium tinggi yang merupakan elemen penting untuk pergerakan feses yang baik. Selain itu anggur hitam juga mempunyai efek antioksidan, antikanker, antiinflamasi, antiaging, dan antimikroba. Berdasarkan analisa sidik ragam menunjukkan bahwa perbedaan proporsi penambahan konjak berpengaruh nyata $(\mathrm{p}<0,05)$ terhadap aktivitas antioksidan pada jeli. Nilai rerata aktivitas antioksidan ditunjukan pada Tabel 8.

Tabel 8. Hasil Uji Aktivitas Antioksidan RSA-DPPH (\%)

\begin{tabular}{|ll|}
\hline Kode Perlakuan & Nilai \\
\hline P1 & $23,95^{ \pm} 0,15^{\mathrm{a}}$ \\
\hline P2 & $25,03^{ \pm} 0,01^{\mathrm{b}}$ \\
\hline P3 & $25,80^{ \pm} 0,19^{\mathrm{c}}$ \\
\hline P4 & $26,07^{ \pm} 0,07^{\mathrm{c}}$ \\
\hline P5 & $27,84^{ \pm} 0,27^{\mathrm{d}}$ \\
\hline P6 & $29,03^{ \pm} 0,06^{\mathrm{e}}$ \\
\hline
\end{tabular}

Keterangan: Superskrip dengan huruf yang berbeda pada kolom yang sama menunjukkan beda nyata $(\mathrm{p}<0,05)$.

Hasil uji lanjut dengan BNJ 5\% menunjukkan bahwa setiap perlakuan memiliki perbedaan yang nyata kecuali perlakuan $3(25,80 \%)$ dan $4(26,07 \%)$ yang tidak berbeda nyata di antara keduanya. Hal ini diduga adanya perbedaan level konsentrasi konjak yang sangat kecil sehingga didapatkan rerata hasil yang tidak berbeda jauh. Penambahan konjak mampu membentuk struktur gel yang lebih rapat sehingga antioksidan yang terkandung masih tetap terjaga tidak terhidrolisis oleh proses.

Rerata nilai aktivitas antioksidan mengalami peningkatan seiring dengan peningkatan konjak yang ditambahkan. Hal ini dimungkinkan karena proporsi konjak yang lebih banyak memiliki kestabilan pembentuk matriks gel yang lebih tinggi dan kuat sehingga antioksidan di dalamnya tidak hilang akibat reaksi hidrolisis produk (Karismawati, dkk, 2015).

\section{Organoleptik Warna}

Suatu bahan yang dinilai bergizi, enak dan teksturnya sangat baik tidak akan dimakan apabila memiliki warna yang tidak sedap dipandang atau memberi kesan telah menyimpang dari warna yang seharusnya. (Winarno, 2004). Berdasarkan analisa sidik ragam menunjukkan bahwa perbedaan proporsi penambahan konjak berpengaruh nyata $(\mathrm{p}<0,05)$ terhadap warna pada jeli. Nilai rerata hasil uji organoleptik warna dilihat pada Tabel 9.

\section{Tabel 9. Hasil Uji Organoleptik Warna}

\begin{tabular}{|lll|}
\hline Kode Perlakuan & Nilai & Keterangan \\
\hline P1 & $3,90^{ \pm} 0,48^{\mathrm{c}}$ & Agak Suka \\
\hline P2 & $4,05^{ \pm} 0,51^{\mathrm{c}}$ & Suka \\
\hline P3 & $3,70^{ \pm} 0,66^{\text {bc }}$ & Agak Suka \\
\hline P4 & $3,45^{ \pm} 0,51^{\text {ab }}$ & Agak Suka \\
\hline P5 & $3,25^{ \pm} 0,44^{\text {a }}$ & Agak Suka \\
\hline P6 & $3,15^{ \pm} 0,37^{\mathrm{a}}$ & Agak Suka \\
\hline
\end{tabular}

Keterangan: Superskrip dengan huruf yang berbeda pada kolom yang sama menunjukkan beda nyata $(\mathrm{p}<0,05)$. 
Hasil uji lanjut dengan BNJ 5\% menunjukkan bahwa perlakuan $1(3,90)$ berbeda nyata dengan perlakuan semua perlakuan kecuali dengan perlakuan $2(4,05)$ dan $3(3,70)$. Perlakuan 2 $(4,05)$ berbeda nyata dengan semua perlakuan kecuali dengan perlakuan $1(3,90)$ dan $3(3,70)$. Perlakuan $3(3,70)$ berbeda nyata dengan semua perlakuan kecuali dengan perlakuan $1(3,90), 2$ $(4,05), 4(3,45)$. Perlakuan $4(3,45)$ berbeda nyata dengan perlakuan $1(3,90)$ dan $2(4,05)$, dan tidak berbeda nyata dengan perlakuan $3(3,70), 5(3,25), 6(3,15)$. Perlakuan $5(3,25)$ berbeda nyata dengan perlakuan $1(3,90), 2(4,05), 3(3,70)$, dan tidak berbeda nyata dengan perlakuan 4 $(3,45)$ dan $6(3,15)$. Perlakuan $6(3,15)$ berbeda nyata dengan dengan perlakuan $1(3,90), 2(4,05)$, $3(3,70)$, dan tidak berbeda nyata dengan perlakuan $4(3,45)$ dan $5(3,25)$. Warna pada jeli dipengaruhi oleh pemanasan pada saat pengolahan, apabila pemanasan dilakukan terlalu lama dalam suhu tinggi maka akan terjadi kerusakan warna pada jeli.

Hal ini terjadi karena semakin banyak konjak yang ditambahkan maka tingkat kesukaan panelis terhadap warna jeli yang dihasilkan semakin rendah. Hal ini diduga karena semakin banyak konjak yang ditambahkan maka jeli akan terlihat semakin keruh dan zat warna yang terkandung dalam anggur akan semakin memudar, sehingga jeli yang dihasilkan tidak lagi berwarna merah keunguan melainkan berwarna merah kecoklatan. Hal ini sejalan dengan pendapat Deptan (2010) bahwa konjak memiliki sifat mudah mengendap. Pada konsentrasi konjak $2 \%$ dihasilkan jeli dengan warna yang tidak terlalu pekat oleh sari anggur, tetapi warna yang dihasilkan masih terlihat menarik minat panelis. Pada konsentrasi konjak $2 \%$ warna yang dihasilkan yaitu ungu. Warna ungu ini didapat karna anggur mengandung banyak senyawa antosianin. Antosianin merupakan kelompok flavonoid yang berperan sebagai pigmen yang memberikan warna ungu pada beberapa buah dan sayuran seperti anggur. Sedangkan pada konsentrasi konjak 6\% dihasilkan jeli dengan warna yang gelap cenderung merah kecoklatan sehingga tidak menarik minat panelis. Warna pada jeli juga dipengaruhi oleh pemanasan pada saat pengolahan , apabila pemanasan dilakukan terlalu lama dalam suhu tinggi maka akan terjadi kerusakan warna pada jeli. Hal ini sesuai dengan pendapat Tenri (2011) bahwa perebusan yang berlebihan menyebabkan penguapan asam, pemecahan pektin, serta kerusakan cita rasa dan warna. Peningkatan konsentrasi pembentuk gel akan meningkatkan tekstur (kekerasan jeli), total asam, meningkatkan kestabilan vitamin $\mathrm{C}$, dan menurunkan kesukaan warna,rasa (Anonim ${ }^{\mathrm{a}}$, 2010).

\section{Organoleptik Tekstur}

Tekstur dari makanan berhubungan dengan konsistensi yang dapat dirasakan, seperti keras, lembut, renyah, halus, kental, menggumpal. Tekstur adalah salah satu dari sifat fisik yang mempengaruhi produk dan penilaian konsumen. Berdasarkan analisa sidik ragam didapatkan hasil bahwa perbedaan proporsi penambahan konjak berpengaruh nyata $(\mathrm{p}<0,05)$ terhadap tekstur jeli. Hasil rerata nilai uji organoleptik tekstur dapat dilihat pada Tabel 10. 
Tabel. 10 Hasil Uji Organoleptik Tekstur

\begin{tabular}{|lll|}
\hline Kode Perlakuan & Nilai & Keterangan \\
\hline P1 & $3,40^{ \pm} 0,50^{\mathrm{ab}}$ & Agak Suka \\
\hline P2 & $4,00^{ \pm} 0,46^{\mathrm{c}}$ & Suka \\
\hline P3 & $3,75^{ \pm} 0,64^{\mathrm{bc}}$ & Agak Suka \\
\hline P4 & $3,50^{ \pm} 0,49^{\mathrm{ab}}$ & Agak Suka \\
\hline P5 & $3,25^{ \pm} 0,44^{\mathrm{a}}$ & Agak Suka \\
\hline P6 & $3,50^{ \pm} 0,51^{\mathrm{ab}}$ & Agak Suka \\
\hline
\end{tabular}

Keterangan: Superskrip dengan huruf yang berbeda pada kolom yang sama menunjukkan beda nyata $(\mathrm{p}<0,05)$.

Hasil uji lanjut dengan BNJ 5\% menunjukkan bahwa perlakuan $1(3,40)$ hanya berbeda nyata dengan perlakuan $2(4,00)$. Perlakuan $2(4,00)$ berbeda nyata dengan semua perlakuan kecuali dengan perlakuan $3(3,75)$. Perlakuan $3(3,75)$ hanya berbeda nyata dengan perlakuan 5 $(3,25)$. Perlakuan $4(3,35)$ hanya berbeda nyata dengan perlakuan $2(4,00)$. Perlakuan $5(3,25)$ berbeda nyata dengan perlakuan $2(4,00), 3(3,75)$. Perlakuan $6(3,50)$ hanya berbeda nyata dengan dengan perlakuan $2(4,00)$. Salah satu penyebab kegagalan jeli untuk mengental disebabkan oleh pemasakan yang terlalu singkat sehingga pengentalan belum tercapai. Adanya hasil uji yang menunjukkan antara perlakuan tidak berbeda nyata, diduga karena proses pemanasan yang kurang sempurna.

Pada konsentrasi konjak 2\% yakni 4,00 (suka) merupakan nilai tertinggi untuk tekstur jeli. Sebaliknya panelis memberikan nilai terendah terhadap tekstur jeli yang konsentrasi konjaknya 5\% yakni 3,25 (agak suka). Hal ini diduga karena pada konsentrasi konjak 2\% mempunyai tekstur lembut, sedikit kenyal tidak seperti agar - agar yang padat. Dengan meningkatnya konsentrasi konjak yang ditambahkan maka semakin keras pula jeli yang terbentuk. Hal ini sesuai dengan pendapat Agustin,dkk (2014), dimana semakin tinggi bahan pembentuk gel yang ditambahkan, maka akan semakin kuat membentuk suatu rantai pengikat pada jaringan sehingga semakin keras gel yang dibentuk.

Pada konsentrasi $1 \%$ memperoleh nilai 3,40 (agak suka) dikarenakan jeli yang dihasilkan terlalu lembek sehingga mudah mencair. Salah satu penyebab kegagalan jeli untuk mengental disebabkan oleh pemasakan yang terlalu singkat sehingga pengentalan belum tercapai. Adanya hasil uji yang menunjukkan antara perlakuan tidak berbeda nyata, diduga karena proses pemanasan yang kurang sempurna. Hal ini sesuai dengan pendapat Anonim ${ }^{a}$ (2010), kegagalan jeli untuk mengental disebabkan oleh ketidakseimbangan antara pembentuk gel, gula, dan asam dan pengaruh garam - garam mineral. Ketidakseimbangan ini dikarenakan kandungan asam atau pembentuk gel atau keduanya sangat rendah, pemasakan yang terlalu singkat sehingga pengentalan belum tercapai dan penambahan air yang terlalu banyak sewaktu penyaringan srai buah sehingga proporsi air terlalu banyak dibanding dengan bahan pembentuk gel. Menurut Malik (2010), jeli merupakan produk pangan yang terbuat dari campuran sari buah, bahan pembentuk gel, dengan bentuk fisik jernih transparan serta tekstur yang kenyal.

\section{Organoleptik Rasa}

Rasa memegang peranan yang sangat penting dalam citarasa pangan dan citarasa merupakan penentu yang handal untuk diterima atau tidaknya suatu produk oleh konsumen. 
Berdasarkan analisa sidik ragam, didapatkan hasil bahwa perbedaan proporsi penambahan konjak berpengaruh nyata $(\mathrm{p}<0,05)$ dengan rasa pada jeli yang dihasilkan. Hasil rerata nilai uji organoleptik rasa dapat dilihat pada Tabel 11.

\section{Tabel. 10 Hasil Uji Organoleptik Rasa}

\begin{tabular}{|lll|}
\hline Kode Perlakuan & Nilai & Keterangan \\
\hline P1 & $3,95^{ \pm} 0,40^{\mathrm{c}}$ & Agak Suka \\
\hline P2 & $4,10^{ \pm} 0,45^{\mathrm{c}}$ & Suka \\
\hline P3 & $3,55^{ \pm} 0,51^{\mathrm{b}}$ & Agak Suka \\
\hline P4 & $3,35^{ \pm} 0,49^{\mathrm{ab}}$ & Agak Suka \\
\hline P5 & $3,20^{ \pm} 0,41^{\mathrm{ab}}$ & Agak Suka \\
\hline P6 & $3,00^{ \pm} 0,00^{\mathrm{a}}$ & Agak Suka \\
\hline
\end{tabular}

Keterangan: Superskrip dengan huruf yang berbeda pada kolom yang sama menunjukkan beda nyata $(\mathrm{p}<0,05)$.

Hasil uji lanjut dengan BNJ 5\% menunjukkan bahwa perlakuan $1(3,95)$ berbeda nyata dengan semua perlakuan kecuali dengan perlakuan $2(4,10)$. Perlakuan $2(4,10)$ berbeda nyata dengan semua perlakuan kecuali dengan perlakuan $1(3,95)$. Perlakuan $3(3,55)$ berbeda nyata dengan perlakuan $1(3,95), 2(4,10)$ dan $6(3,00)$. Perlakuan $4(3,35)$ berbeda nyata dengan perlakuan $1(3,95)$ dan $2(4,10)$. Perlakuan $5(3,20)$ berbeda nyata dengan perlakuan $1(3,95)$ dan $2(4,10)$. Perlakuan $6(3,00)$ berbeda nyata dengan semua perlakuan kecuali dengan perlakuan 4 $(3,35)$ dan $5(3,20)$.

Semakin rendah konsentrasi konjak yang ditambahkan maka rasa asam dari sari anggur hitam akan lebih dominan. Perlakuan ke 2 mendapat nilai tertinggi karena rasa yang dihasilkan tidak terlalu asam. Sedangkan perlakuan ke 6 mendapat nilai terendah karena rasa yang dihasilkan hambar tidak terasa sari anggurmya. Rasa yang dihasilkan dipengaruhi oleh konsentrasi konjak yang ditambahkan, karena konjak ini berasa tawar (Putra, 2013), semakin banyak konjak yang ditambahkan maka akan menutupi rasa asam dari sari anggur hitam tersebut. Semakin sedikit konjak yang ditambahkan dibanding sari anggur maka semakin banyak kadar air pada jeli, dengan semakin banyak air yang terkandung maka diduga semakin banyak senyawa senyawa flavor pada anggur yang terhidrolisis, sehingga rasa anggur pada jeli akan semakin berkurang. Hal ini sejalan dengan pendapat Anonima (2010), peningkatan konsentrasi pembentuk gel akan meningkatkan tekstur (kekerasan jeli), total asam, meningkatkan kestabilan vitamin C, dan menurunkan kesukaan warna, rasa.

\section{KESIMPULAN}

Kesimpulan dari penelitian ini adalah sebagai berikut :

1. Perbedaan proporsi penambahan konjak pada pembuatan jeli berpengaruh nyata terhadap aktivitas antioksidan, vitamin $\mathrm{C}$, kadar air, tekstur (kekerasan, elastisitas, kekenyalan) sineresis, dan organoleptik (rasa, tekstur, dan warna).

2. Hasil perlakuan paling diminati adalah perlakuan ke 3 dengan aktivitas antioksidan $25,80 \%$, vitamin C $1,75 \mathrm{mg} / \mathrm{g}$, kadar air 19,24\%, kekerasan 428,27 gf, elastisitas $9,26 \mathrm{~N} / \mathrm{m}^{2}$, kekenyalan 118,49 gf, sineresis 2,91\%, skor rasa 3,55, skor tekstur 3,75, skor warna 3,70. 


\section{SARAN}

Dari hasil penelitian saya dapat dilanjutkan penelitian selanjutnya dengan menggunakan bahan pengental lain, sehingga dapat membandingkan antara jenis bahan pengental dan dapat menentukan bahan pengental terbaik untuk pembuatan jeli.

\section{DAFTAR PUSTAKA}

Agustin, Firdausia dan Widya Dwi Rukmi Putri. 2014. Pembuatan Jelly Drink Averrhoa blimbi L. (Kajian Proporsi Belimbing Wuluh : Air Dan Konsentrasi Karagenan). Jurnal Pangan dan Agroindustri. Vol. 2. No. 3. Jurusan Teknologi Hasil Pertanian. Universitas Brawijaya. Malang.

Anonim $^{\text {a }}$ 2010. Cara Sederhana Membuat Jam Dan Jell. http://amiere.multiply.com/journal/item. Diakses tanggal 3 Februari 2018, Semarang.

Anonim. 2018. Manfaat Buah Anggur. www.bugarfit.com. Diakses tanggal 21 Januari 2018.

Azizah, Nurul Hidayah. 2012. Pembuatan Permen Jelly Dari Karagenan Dan Konjak Dengan Aplikasi Prebiotik Xilo-Oligosakarida. Skripsi. Fakultas Teknologi Pertanian. Institut Pertanian Bogor. Bogor.

Departemen Pertanian. 2010. Multifungsi Glukomannan dari Umbi Iles-Iles. Jakarta : Departemen Pertanian.

Imeson AP. 2000. Carrageenan dalam Handbook of Hydrocolloids. GO Phillips dan PA Williams (ed). New York : CRC Press.

Karismawati,Aulia Shabrina, Nirmala Nurhasanah, Tri Dewanti Widyaningsih. 2015. Pengaruh Minuman Fungsional Jelly Drink Kulit Buah Naga Merah Dan Rosella Terhadap Stres Oksidatif. Jurnal Pangan dan Agroindustri. Vol.3. No. 2. Jurusan Teknologi Hasil Pertanian. Universitas Brawijaya. Malang.

Koswara, Sutrisna. (2011). Cara Sederhana Membuat Jam dan Jelly. http://pustakapanganku. blogspot.com/2011/06/cara-sederhana-membuat- jam dan- jelly.html. Diakses 11 Maret 2018.

Malik. 2010. Permen Jelly. http://www. malik. wordpress.com. Diakses tanggal 11 Februari 2018.

Muchtadi, T.R. dan Sugiono. 1992. Ilmu Pengetahuan Bahan Pangan. Departemen Pendidikan dan Kebudayaan. Direktorat Jenderal Tinggi Pusat Antar Universitas Pangan dan Gizi. IPB. Bogor

Putra, Bagus Prahara. 2013. Pengaruh Jenis Dan Proporsi Bahan Pembentuk Gel Terhadap Hasil Jadi Minuman Jeli Kunyit Asam. Ejournal Boga. Vol. 2. No. 1. Fakultas Teknik. Universitas Negri Surabaya. Surabaya.

Rosenthal AJ. 1999. Food Texture : Measurement and Perception. Maryland: Aspen Publisher. Inc. Salamah E, Erungan AC, dan Retnowati Y. 2006. Pemanfaatan gracialia sp. dalam pembuatan permen jelly. Buletin Teknologi Hasil Perikanan Vol. IX No.1.

Tako M dan Nakamura S. 1988. Synergistic interaction between agarose and D- galacto-Dmannan in aqueous media. J Agricultural and Biological Chemistry 52 : 1071-1072.

Tenri, Andri. 2011. Pembuatan Jelly. http://anditenriptbp.blogspot.com/2011/02/pembuatanjelly. Diakses tanggal 20 Februari 2018.

Thomson WR. 1997. Konjac Gum di dalam Thickening and Gelling Agents for Food. Imerson AP (ed). London: Blackie Academic and Professional.

Widyaningtyas, M. dan Susanto,W. H. 2014. Pengaruh jenis dan konsentrasi hidrokoloid (carboxy methyl cellulose, xanthan gum, dan karagenan) terhadap karakteristik mie 
kering berbasis pasta ubi jalar varietas asekuning. Jurnal Pangan dan Agroindustri. 3 (2) : $417-423$.

Winarno, F. G. 1992. Kimia Pangan dan Gizi. Jakarta: PT. Gramedia Pustaka Utama.

Winarno, F.G. 1997. Kimia Pangan dan Gizi. Gramedia pustka utama. Jakarta

Winarno, F.G. 2004. Kimia Pangan dan Gizi. Gramedia pustaka utama. Jakarta. Liberty. Yogyakarta. 